\title{
A CONVENÇÃO 169 DA OIT E O CONTROLE DE CONVENCIONALIDADE NOS TRIBUNAIS DA REGIÃO NORTE DO BRASIL
}

\section{Daize Fernanda Wagner ${ }^{1}$}

\section{RESUMO:}

Discute a aplicação da Convenção 169 sobre Povos Indígenas e Tribais da Organização Internacional do Trabalho (OIT) e o controle difuso de convencionalidade no âmbito dos Tribunais de Justiça dos estados da Região Norte do Brasil. O objetivo é analisar como julgam os tribunais em casos nos quais a identidade étnica e a pertença de indígenas aparecem como assunto relevante, apto a influenciar sua decisão. Observou-se que a Convenção 169 da OIT pouco ou nunca é mencionada nos julgados. A metodologia utiliza abordagem qualitativa, baseada em pesquisa bibliográfica e documental, sendo utilizado o método indutivo na catalogação de julgados.

PALAVRAS CHAVE: Controle de Convencionalidade; Convenção 169 da OIT; Identidade Étnica; Autoidentificação; Tribunais de Justiça da região Norte.

\section{ILO'S CONVENTION N. 169 AND THE CONVENTIONALITY CONTROL IN THE NORTH REGION COURTS OF BRAZIL}

\begin{abstract}
:
It intends to discuss the application of the Convention 169 on Indigenous Peoples and Tribes of the International Labor Organization (ILO) and the diffuse control of conventionality within the scope of the Law Courts of the North Region in Brazil. The objective is to analyze how these courts adjudge cases that involve ethnic identity and the indigenous' ownings appear as a relevant issue, in order to influence their decision. It was observed that ILO's Convention 169 is little or never mentioned in the judicial precedents. The qualitative approach was the methodology used, based on bibliographical and documentary research.
\end{abstract}

KEYWORDS: Conventionality Control; ILO’s Convention no. 169; Ethnical Identity; Self Identification, Law Courts of the North Region

\section{INTRODUÇÃO ${ }^{2}$}

O presente trabalho objetiva discutir a aplicação da Convenção 169 sobre Povos Indígenas e Tribais da Organização Internacional do Trabalho (OIT) e o controle difuso de

\footnotetext{
${ }^{1}$ Professora Adjunta no curso de Direito e Colaboradora no Programa de Pós-Graduação em Estudos de Fronteira (PPGEF) da Universidade Federal do Amapá (UNIFAP). Doutora em Direito pela Universidade Federal de Minas Gerais (UFMG). Mestre em Direito pela Ludwig Maximilian Universität (LMU) Munique/Alemanha. Líder do Grupo de Pesquisa Direitos Humanos, Cidadania e Justiça - CNPQ/UNIFAP. Macapá, Amapá, Brasil. E-mail: daizefernandawagner@gmail.com

${ }^{2}$ A coleta de dados contou com a colaboração de Jéssica Araújo do Carmo e Mário Guilherme Corrêa Jennings, estudantes do curso de Direito da UNIFAP, bolsistas do Projeto.
} 
convencionalidade no âmbito dos Tribunais de Justiça dos estados que integram a Região Norte do Brasil, quando chamados a se pronunciar sobre casos envolvendo indígenas. Esta pesquisa é resultado parcial das investigações desenvolvidas no Projeto Identidades Étnicas em Juízo, registrado e financiado pela Universidade Federal do Amapá (UNIFAP).

O objetivo da pesquisa é analisar como julgam os tribunais pátrios em casos em que a identidade étnica e a pertença de indígenas aparecem como assunto relevante a ponto de influenciar sua decisão e o reconhecimento de direitos aos indígenas. No andamento da investigação, observou-se que a Convenção 169 da OIT pouco ou nunca é mencionada nos julgados, a despeito de integrar o ordenamento jurídico brasileiro, na medida em que foi ratificada em 2002 e entrou em vigor doze meses após sua ratificação.

A Convenção 169 da OIT promove o reconhecimento aos Povos Indígenas, em sentido próximo àquele previsto na Constituição da República Federativa do Brasil de 1988 $(\mathrm{CF} / 88)$, que trouxe grande inovação ao reconhecer aos indígenas sua organização social, costumes, línguas, crenças e tradições, bem como os direitos originários sobre as terras que tradicionalmente ocupam, nos termos do artigo 231. Rompeu, assim, com a percepção assimilacionista e de aculturação que até então estavam em vigor, tal como previa o Estatuto do Índio (Lei n. 6.001/1973) e a ultrapassada Convenção 107 da OIT. A partir da CF/88 e da Convenção 169 da OIT, os indígenas tem direito de serem e se manterem indígenas (SOUZA FILHO, 1998).

A discussão que se coloca possui dois níveis de dificuldade envolvidos: um que se refere ao cumprimento e aplicação das normas constitucionais, portanto, do ordenamento interno do próprio Estado brasileiro, e outro, que diz respeito às normas de proteção a direitos humanos em nível internacional e, no caso, especificamente a Convenção 169 da OIT.

Nessa direção, o problema que orienta o presente trabalho indaga acerca da efetividade das normas previstas na Convenção 169 da OIT. Os magistrados que integram os Tribunais estaduais da Região Norte observam e aplicam a Convenção 169 da OIT em suas decisões?

Seria possível argumentar a desnecessidade de recorrer-se a normas de direito internacional nos casos analisados e, assim, afirmar tratar-se apenas de problema de direito interno, na medida em que a CF/88, principalmente nos artigos 231 e 232, foi expressa no reconhecimento de direitos aos indígenas. Todavia, compreende-se necessário analisar os casos também à luz do direito internacional, na medida em que é a Convenção 169 da OIT, 
que claramente estabelece a autoidentificação como suficiente para o reconhecimento da identidade étnica dos indígenas. Além disso, é necessário que se compatibilize e concretize a aplicação das normas internacionais de direitos humanos pelas cortes nacionais, para que se atinja a plenitude da garantia do respeito à dignidade humana, valor tão caro e que ilumina todo o ordenamento jurídico brasileiro.

A presente pesquisa compreende, com Gustin e Dias (2013), que "[t]oda opção metodológica supõe uma concepção provisória da realidade a ser conhecida" (GUSTIN; DIAS, 2013, p. 19). Portanto, o presente olhar é fruto do estágio atual da pesquisa, ainda em desenvolvimento. Como metodologia, utiliza-se uma abordagem qualitativa baseada em pesquisa bibliográfica e em pesquisa documental, sendo utilizado o método indutivo na catalogação de julgados.

\section{A CONVENÇÃO 169 DA OIT E SUA APLICABILIDADE NO BRASIL}

A Convenção 169 da OIT entrou em vigor em 05/09/1991, tendo sido aprovada, em 1989, por 328 votos favoráveis contra 49 abstenções. O Brasil foi um dos países que se absteve. Ela foi ratificada pelo Brasil somente em 2002, entrando em vigor doze meses após sua ratificação. Adentrou nosso ordenamento jurídico através do Decreto Legislativo n. 143, de 20/06/2002 e do Decreto Presidencial n. 5.051, de 19/04/2004. Integra, portanto, o ordenamento jurídico brasileiro, devendo ser aplicada. (WAGNER, 2014).

A Convenção 169 da OIT foi aprovada em substituição à Convenção 107. Esta foi a primeira Convenção da OIT a tratar amplamente dos direitos dos povos indígenas. Antes dela havia convenções que tratavam de assuntos específicos envolvendo os povos indígenas, mas de forma pontual. Assim, por exemplo, a Convenção n. 50 da OIT tratava do recrutamento de trabalhadores indígenas, a Convenção n. 65, de 1939, tratava sobre as sanções penais, a Convenção n. 105, de 1957, sobre a abolição do trabalho forçado etc. (WAGNER, 2014).

Ou seja, de maneira geral, a OIT, através de suas Convenções, que são seu principal instrumento legislativo, sempre procurou tratar de aspectos relacionados à melhoria de vida e dignidade dos povos indígenas. Inicialmente, considerando os indígenas apenas enquanto força de trabalho, mão de obra que necessitava ter alguns direitos resguardados. Após, de maneira bem mais ampla, como é o caso da atual Convenção 169 da OIT. 
Importante ponto de avanço desta Convenção em relação a sua antecessora é o reconhecimento à autoidentificação, ou seja, os Estados-parte não podem negar a identidade a um povo indígena ou tribal que se reconhece a si próprio como tal. É o que estabelece o artigo $1^{\circ}$, item 2, da Convenção 169, conforme segue:

\section{A presente convenção aplica-se:}

a) aos povos tribais em países independentes, cujas condições sociais, culturais e econômicas os distingam de outros setores da coletividade nacional, e que estejam regidos, total ou parcialmente, por seus próprios costumes ou tradições ou por legislação especial;

b) aos povos em países independentes, considerados indígenas pelo fato de descenderem de populações que habitavam o país ou uma região geográfica pertencente ao país na época da conquista ou da colonização ou do estabelecimento das atuais fronteiras estatais e que, seja qual for sua situação jurídica, conservam todas as suas próprias instituições sociais, econômicas, culturais e políticas, ou parte delas.

2. A consciência de sua identidade indígena ou tribal deverá ser considerada como critério fundamental para determinar os grupos aos que se aplicam as disposições da presente Convenção.

3. A utilização do termo "povos" na presente Convenção não deverá ser interpretada no sentido de ter implicação alguma no que se refere aos direitos que possam ser conferidos a esse termo no direito internacional. (grifamos)

Enquanto a Convenção 107 da OIT era identificada com seus objetivos de proteção e integração dos povos indígenas, a Convenção 169 pode ser identificada com os objetivos do respeito e participação. Esta Convenção está alinhada tanto com o respeito à diferença, quanto ao direito de participação e de consulta aos povos indígenas em relação a todas as ações legislativas e administrativas que possam afetá-los de alguma maneira. Têm direito de definir suas próprias prioridades de desenvolvimento, levando em conta tudo que afete sua forma de vida, cultura, crença, valores, instituições e sua relação com a terra que habitam. (WAGNER, 2014).

A Convenção está em pleno vigor e deve ser aplicada, especialmente no aspecto que mais interessa à presente discussão, que é o reconhecimento a autoidentificação como critério suficiente para se afirmar a identidade étnica de uma pessoa ou de um grupo de pessoas indígenas, nos termos de seu artigo $1^{\circ}$, item 2 , acima transcrito.

Outro ponto importante acerca da Convenção 169 da OIT e sua aplicabilidade no Brasil refere-se a seu status normativo. A Convenção 169 da OIT é tratado internacional de direitos humanos, na medida em que é um tratado multilateral aberto (SILVA, 2010), que foi devidamente ratificado pelo Brasil. Versa sobre direitos humanos, pois trata de forma ampla 
de diferentes direitos assegurados a povos indígenas e tribais, de maneira a possibilitar-lhes vida digna, reconhecimento e continuidade de suas gerações futuras.

O Supremo Tribunal Federal (STF), ao proferir decisão majoritária no Habeas Corpus (HC) n. 87.585/TO e no Recurso Extraordinário (RE) n. 466.343/2005, estabeleceu o entendimento de que tratados internacionais de direitos humanos possuem status supralegal independentemente do quórum com o qual tenham sido ratificados. Seguindo esse entendimento, então, a Convenção 169 da OIT se caracteriza por ser tratado internacional de direitos humanos e por ter status supra legal, estando abaixo da $\mathrm{CF} / 88$, mas acima de leis ordinárias, como é o caso do Estatuto do Índio (Lei n. 6001/1973), por exemplo. Esse aspecto é importante para a análise dos julgados dos Tribunais da Região Norte, como se verá.

Nesse cenário, o controle judicial de convencionalidade adquire particular relevo, por ser instrumento eficaz para o respeito, a garantia e a efetivação dos direitos descritos nos tratados internacionais de direitos humanos, como é o caso da Convenção 169 da OIT, na medida em que as normas locais devem guardar compatibilidade com a ordem humanitária internacional. (VAL; OLIVEIRA, 2016).

\section{O CONTROLE JURISDICIONAL DIFUSO DE CONVENCIONALIDADE E A CONVENÇÃO 169 DA OIT}

O controle de convencionalidade consiste num procedimento de averiguação da compatibilidade das normas e práticas internas em cotejo com os tratados internacionais e os parâmetros interpretativos emanados das cortes internacionais. (VAL; OLIVEIRA, 2016). Implica em uma hermenêutica que integre a norma internacional ao ordenamento jurídico interno, de maneira a efetivar compromissos assumidos pelo Estado quando ratifica a norma internacional. Sua prática vai em sentido inverso ao da fragmentação do direito e, por isso, ainda encontra resistência, a despeito do que estabelece o artigo $5^{\circ}, \S 2^{\circ}$ da $\mathrm{CF} / 88$. Nesse sentido, entre outros, Bohmer (2007), Abramovich (2009) e Leal; Alves (2017).

O controle difuso de convencionalidade é procedimento semelhante ao controle difuso de constitucionalidade. O que se modifica é seu parâmetro de medida: naquele, são as obrigações internacionais assumidas a partir de tratados e convenções ratificados pelo Brasil e neste, a supremacia da $\mathrm{CF} / 88$. Sendo difuso, pode ser realizado por todos os órgãos do Poder Judiciário, dentro de sua respectiva competência e em conformidade com os 
procedimentos estabelecidos pela ordem jurídica. "No Brasil, todo e qualquer juiz ou tribunal, mesmo em sede de jurisdição ordinária, tem o dever (ex officio) de analisar a convencionalidade da norma interna" (LEAL; ALVES, 2017, p. 115; MAZZUOLI, 2011, p. 151).

Segundo Mac-Gregor (2010) e também Val; Oliveira (2016), os juízes nacionais são os verdadeiros guardiões da convencionalidade. Isso é justamente o que caracteriza o controle difuso de convencionalidade. Assim, como justificar que tais guardiões sequer mencionem a norma internacional, ratificada e em vigor no Brasil, em seus julgados?

A incorporação das normas de direito internacional não se dá de maneira automática no âmbito interno. Para além de todo o procedimento formal de ingresso no direito interno, há um importante papel desempenhado por diferentes atores sociais, políticos e jurídicos, que vão contribuir ativamente para que as normas internacionais tenham aplicação no plano interno. Nessa direção aponta Abramovich (2009), que afirma:

\footnotetext{
[...] essas normas internacionais se incorporam no âmbito nacional pela ação dos Congressos, governos, sistemas de justiça e também com a participação ativa de organizações sociais que promovem, demandam e coordenam essa aplicação nacional com as diversas instâncias do Estado. A aplicação de normas internacionais no âmbito nacional não é um ato mecânico, mas um processo que envolve também diferentes tipos de participação e deliberação democrática e inclui uma ampla margem para a releitura ou reinterpretação dos princípios e normas internacionais em função de cada contexto nacional. (ABRAMOVICH, 2009, p. 25)
}

No caso específico da Convenção 169 da OIT, pode-se citar como exemplo dessa mobilização, desse pôr em marcha a aplicação da norma internacional em âmbito interno, a atuação dos povos indígenas, que passaram a elaborar seus protocolos de consulta prévia, de maneira a possibilitar a efetivação do direito previsto no artigo $6^{\circ}$ da Convenção.

$\mathrm{O}$ artigo $6^{\circ}$ da Convenção 169 da OIT estabelece que os governos deverão consultar os povos indígenas, por procedimentos adequados e através de suas instituições representativas, sempre que sejam previstas medidas legislativas ou administrativas suscetíveis de afetá-los diretamente. Ainda segundo esse artigo, os governos devem criar meios pelos quais esses povos possam participar livremente, ou pelo menos na mesma medida assegurada aos demais cidadãos, em todos os níveis decisórios de instituições eletivas ou órgãos administrativos responsáveis por políticas e programas que lhes afetem. $\mathrm{O}$ artigo $6^{\circ}$ afirma ainda que os governos devem estabelecer meios adequados para o pleno desenvolvimento das instituições e iniciativas próprias desses povos e, quando necessário, 
disponibilizar os recursos necessários para esse fim. Estabelece ainda que as consultas a serem realizadas devem ser conduzidas de boa-fé e de uma maneira adequada às circunstâncias, no sentido de que um acordo ou consentimento em torno das medidas propostas possa ser alcançado. (BRASIL, 2004).

$\mathrm{O}$ direito à consulta e ao consentimento livre, prévio e informado é considerado pedra angular da Convenção 169 (GLASS, 2019). Para assegurar sua efetividade, vários povos indígenas passaram a elaborar documentos com orientações claras ao Estado e aos nãoíndios acerca da maneira pela qual devem ser consultados. Esses documentos são chamados de Protocolos de Consulta Prévia. O povo Wajãpi, no estado do Amapá, foi o primeiro a elaborar seu Protocolo, em agosto de 2014. Depois dele, vários outros foram sendo elaborados e $\operatorname{adotados}^{3}$, demonstrando justamente a importância da mobilização dos atores sociais, jurídicos e políticos na aplicação da norma de direito internacional no direito interno.

Esse é apenas um exemplo que ilustra maneiras de efetivar a aplicação do direito internacional em âmbito interno. Dito isso, interessa investigar em que medida a mesma Convenção 169 da OIT, mas no que se refere a outro dispositivo, tem sido reconhecida e adotada por órgãos do Poder Judiciário pátrio: o artigo $1^{\circ}$, item 2 , que estabelece a autoidentificação como suficiente para o reconhecimento da identidade étnica própria aos indígenas. Este tem sido o cerne da pesquisa desenvolvida no projeto Identidades Étnicas em Juízo, na UNIFAP. Todavia, antes de discorrer acerca da pesquisa em desenvolvimento, necessário delimitar um de seus pressupostos, que é a identidade étnica indígena.

\section{A IDENTIDADE ÉTNICA INDÍGENA}

A noção de identidade étnica indígena é central na pesquisa em desenvolvimento. Ela pode ser considerada um constructo que foi se delineando ao longo do tempo, a partir da contribuição de vários estudiosos de diferentes campos e, principalmente, do protagonismo de vários indígenas.

Considera-se que a Convenção 169 da OIT, ao estabelecer que a autoidentificação é a maneira adequada para identificar os indígenas, cristalizou tal noção na legislação. A partir

\footnotetext{
${ }^{3}$ Exemplo da aplicação dos Protocolos e, portanto, de sua força vinculante pode ser observado na decisão do TRF da Primeira Região na Apelação Civel n. 0002505-70.2013.4.01.3903/PA, que reconheceu o dever do estado do Pará de consultar o Povo Juruna previamente e suspendeu o procedimento de licenciamento ambiental de empreendimento da Mineradora Belo Sun. (BRASIL, 2017)
}

Rev. de Direitos Humanos em Perspectiva | e-ISSN: 2526-0197 | Evento Virtual | v. 6 | n. 1 | 
dela, então, ser indígena deveria decorrer apenas dessa autoidentificação refletida no respectivo grupo étnico e, portanto, o critério fundado na cultura para definir a pertença étnica não pode mais ser utilizado. Aliás, essa ideia há muito foi abandonada por estudiosos de outras áreas, a exemplo da Antropologia, como se procurará demonstrar.

A noção de etnia se encontra desde sempre mesclada a outras concepções que lhe são conexas como as de raça, povo e nação, com as quais mantém relações de ambiguidade desde o início de seu uso pelas ciências sociais, no século XIX. (POUTIGNAT; STREIFFFENART, 1998).

O culturalismo representou ruptura em relação às concepções fundadas na ideia de raça. A partir dele, ganharam espaço as teorias que buscavam nas expressões culturais a explicação para a pertença a grupos e para as diferenças entre os grupos étnicos entre si e em relação às sociedades nas quais estavam inseridos. Segundo tais teorias, grosso modo, era a cultura que forjava as identidades. Cultura aqui entendida como conjunto de valores, formas e expressões partilhadas por determinado grupo, que os diferencia dos demais (CUNHA, 1987). A existência de crenças ou de uma língua comum exclusiva utilizada pelo grupo, embora não fossem consideradas imprescindíveis, eram tidas como importantes traços diferenciadores do grupo étnico. Nesse sentido, Cunha (1987) e Poutignat; Streiff-Fenart (1998). (WAGNER, 2019).

Os critérios fundados em traços culturais mostraram-se inadequados para estabelecer os grupos étnicos e diferenciar as identidades indígenas por várias razões, das quais Cunha (1987) destaca três: a impermanência dos traços culturais no tempo e a possibilidade de existirem diferentes traços culturais num mesmo grupo étnico, conforme sua situação ecológica e social. Essa "instabilidade" dos traços culturais pode ocorrer na adaptação às condições naturais e às oportunidades sociais originadas na interação com outros grupos o que, por si só, não altera a identidade étnica própria do grupo. (WAGNER, 2019).

Além disso, quando há situações de contato intenso do grupo étnico com a sociedade na qual está inserido, como ocorre com indígenas de diferentes etnias em diferentes regiões do Brasil, acabam levando a que estes resistam às interferências através do apego a determinados traços culturais. Esses traços culturais foram chamados por Barth (1969) de sinais diacríticos, que são, então, enfatizados e preservam, assim, a identidade do grupo. Entre os diferentes estudos antropológicos realizados, verificou-se algo em comum: a impossibilidade de afirmar quais sinais diacríticos, dentre todos os possíveis no grupo, seriam 
enfatizados. Segundo Cunha (1987), então, essa imprevisibilidade seria mais um argumento, o terceiro, a depor contra o uso da cultura como o princípio primeiro de um grupo étnico. (WAGNER, 2019).

Precursor desse debate, Max Weber (1994), na obra Economia e Sociedade, de 1922, dedicou o capítulo "Comunidades Étnicas" ao tema. A partir de Weber, então, é possível afirmar que grupos étnicos existem pela crença subjetiva que têm seus membros de formar uma comunidade e pelo sentimento de honra social compartilhado por todos que alimentam essa crença. A identidade étnica do grupo é construída a partir da diferença em relação aos outros, que não compõe o grupo. Há como que uma atração entre os que se sentem parte do "nós" e uma repulsa em relação aos que são "outros". A pertença, então, não está fundada no isolamento, mas antes na comunicação das diferenças em relação aos outros.

Essa ideia de pertença étnica descrita por Weber será apropriada e desenvolvida por Fredrik Barth (1969). Avançando na ideia da cultura como traço distintivo da identidade étnica, "Barth vai perceber que nem os grupos étnicos se definem por portarem culturas específicas nem o contato dilui as etnias" (SILVA, 2005, p. 30). Barth propõe uma nova definição de grupos étnicos, segundo a qual, então,

\begin{abstract}
As fronteiras [entre os grupos étnicos] persistem apesar do fluxo de pessoas que as atravessam. [...] As distinções de categorias étnicas não dependem de uma ausência de mobilidade, contato e informação. [...] As distinções étnicas não dependem de uma ausência de interação social e aceitação, mas são, muito ao contrário, frequentemente as próprias fundações sobre as quais são constituídos os sistemas sociais englobantes. A interação em um sistema social como este não leva a seu desaparecimento por mudança e aculturação; as diferenças culturais podem permanecer apesar do contato interétnico e da interdependência dos grupos. [...] Os grupos étnicos são categorias de atribuição e identificação realizadas pelos próprios atores e, assim, têm a característica de organizar a interação entre as pessoas. [...] Uma atribuição categórica é uma atribuição étnica quando classifica uma pessoa em termos de sua identidade básica mais geral, presumivelmente determinada por sua origem e seu meio ambiente. Na medida em que os atores usam identidades étnicas para categorizar a si mesmos e outros, com objetivos de interação, eles formam grupos étnicos neste sentido organizacional. (BARTH, 1998, p. 188, 189, 193-194, grifo nosso).
\end{abstract}

Barth substituiu uma concepção estática de identidade étnica por uma concepção dinâmica. A partir de seus estudos foi possível compreender que a identidade étnica, tal como outras identidades coletivas, é construída e transformada na interação de grupos sociais, seja em processos de inclusão, seja de exclusão, sempre numa dinâmica de se estabelecer os 
limites entre tais grupos e aqueles que os integram ou não. (POUTIGNAT; STREIFFFENART, 1998).

Havia, então, a compreensão de que a identidade étnica seria estática, fixada em características imutáveis. Todavia, como sugere Silva (2005), é preciso insistir na importância da ampliação do entendimento do conceito de identidade étnica - "[i]dentidade não é sinônimo de unicidade." (SILVA, 2005, p. 44). Aí reside relevância dos estudos de Barth, que compreendeu que os processos de organização social através dos quais mantêm-se de forma duradoura as distinções entre "nós" e "os outros" podem se alterar e que tais alterações não são capazes de suprimir a diferença entre o "nós" e "os outros". (LAPIERRE, 1998): "as diferenças culturais podem permanecer apesar do contato interétnico e da interdependência dos grupos". (BARTH, 1998, p.188).

Para Barth, o traço fundamental dos grupos étnicos é a atribuição e a pertença. Assim, pouco importa que traços culturais ou outras diferenças "objetivas" se modifiquem e pouco importa as diferenças que os membros do grupo possam ter em seus comportamentos manifestos: "se eles dizem que são A, em oposição a outra categoria B da mesma ordem, eles estão querendo ser tratados e querem ver seus próprios comportamentos interpretados e julgados como de As e não de Bs, ou seja, eles declaram sua sujeição à cultura compartilhada pelos As.” (BARTH, 1998, p. 195).

Então, em síntese, com Barth é possível afirmar que grupos étnicos são organizações sociais cujas fronteiras se definem pelo pertencimento que cada ator manifesta em relação ao grupo, mesmo que os sinais diacríticos possam se modificar. Os traços culturais devem ser compreendidos muito mais como produzidos pelo grupo do que como formatadores da identidade étnica do grupo. Portanto, é indígena quem se considera e é considerado indígena por seu grupo. (CUNHA, 1987). Essa compreensão repercutiu juridicamente e considera-se que está na base da definição de quem é indígena na Convenção 169 da OIT, artigo $1^{\text {o }}$, item 2.

Se por um lado a identidade étnica indígena é afirmada pelo próprio indígena e pelo grupo do qual faz parte, por outro, implica em reconhecimento pelos demais, que não integram aquele grupo étnico. Esse é o aspecto relacional da noção de identidade étnica, também enfatizado por Luciano:

Ora, identidade implica a alteridade, assim como a alteridade pressupõe diversidade de identidades, pois é na interação com o outro não-idêntico que a identidade se constitui. O reconhecimento das diferenças individuais e coletivas é condição de cidadania quando as identidades diversas são reconhecidas como direitos civis e 
políticos, consequentemente absorvidos pelos sistemas políticos e jurídicos no âmbito do Estado Nacional. (LUCIANO, 2006, p. 49).

Se a formação e manutenção de nossa identidade se dá na alteridade, então, o reconhecimento tornar-se central na discussão acerca da identidade, inclusive étnica. Da mesma forma, a ausência de reconhecimento pode efetivamente causar prejuízo ao grupo ou à pessoa que o sofre. (WAGNER, 2019). Desvelar a maneira pela qual o Poder Judiciário reconhece a identidade étnica de indígenas é o principal escopo da pesquisa desenvolvida no Projeto Identidades Étnicas em Juízo.

\section{A PESQUiSA DESENVOLVIDA NO PROJETO IDENTIDADES ÉTNICAS EM Juízo}

O projeto Identidades Étnicas em Juízo atua como um observatório de jurisprudência e, portanto, é atividade de pesquisa que combina, a um só tempo, investigação científica com ferramenta de controle social. As decisões proferidas por juízes e tribunais impactam na vida social e são capazes de mudar a postura do país sobre determinados temas. (MEDEIROS; PETTERLE, 2015) Assim, investigar como julgam os tribunais toma relevo e pode contribuir para a transparência acerca das decisões e na consolidação do Estado Democrático de Direito, fundado na dignidade da pessoa humana e comprometido com a construção de uma sociedade livre, justa e solidária, que visa promover o bem de todos, nos termos da CF/88.

Ao proferirem suas decisões, os tribunais estão delineando conteúdos acerca da identidade étnica indígena e dando efetividade (ou não) aos direitos assegurados aos povos indígenas na CF/88 e também na Convenção 169 da OIT. Desvelar os sentidos da identidade étnica presentes em julgados implica em utilizar-se de um olhar marcado pelo estranhamento, que é essencialmente o olhar antropológico, conforme aponta Lima; Baptista (2014). Estranhamento esse que não significa suspeição, mas sim surpreender-se com tudo o que para o outro parece natural. "O fazer antropológico pressupõe a relativização de verdades consagradas.” (LIMA; BAPTISTA, 2014, p. 9). Esse estranhamento pode ser interessante mecanismo para desnaturalizar a interpretação das normas jurídicas no que tange à temática indígena pelo Judiciário.

Nesse percurso, a tentativa é dupla, conforme proposto por Bardin (1977), aqui adaptado à presente pesquisa: compreender o sentido da norma, sua concretização pelo Poder 
Judiciário e também, principalmente, “desviar o olhar para uma outra significação, uma outra mensagem entrevista através ou ao lado da mensagem primeira”. (BARDIN, 1977, p. 41). Assim, para além da leitura da letra posta nos julgados, pretende-se compreender o sentido que se encontra em segundo plano, que tem relação com a maneira como o Poder Judiciário compreende a identidade étnica indígena e efetiva os direitos próprios aos indígenas.

Essa é a descrição sumária do objetivo do projeto, que tem analisado decisões dos Tribunais estaduais de diferentes regiões do país sobre como a identidade e a pertença étnica de indígenas é considerada.

$\mathrm{Na}$ análise dos julgados passou-se a observar que a Convenção 169 da OIT quase ou nunca é mencionada nos acórdãos. Tal fato ganhou destaque e passou a ser investigado. Ora, se o artigo $1^{\circ}, 2$, da Convenção 169 da OIT estabelece a autoidentificação como critério suficiente ao reconhecimento da identidade indígena, o questionamento acerca da suposta aculturação dos indígenas não deveria ter lugar. Todavia, não é o que se verificou na maioria dos julgados analisados. ${ }^{4}$

Inicialmente, os julgados foram coletados nos endereços eletrônicos dos tribunais estaduais da região Norte do país, a partir dos seguintes termos de busca: índio(s), indígena(s), silvícola(s), aborígine(s) e autóctone(s). Tais termos foram escolhidos pois são usualmente utilizados para referir os indígenas, seja individualmente, seja coletivamente. Para a análise são considerados apenas os julgados que de algum modo apresentam argumentos vinculados à identidade étnica indígena e as maneiras que ela é compreendida pelos julgadores. O critério de seleção dos casos é a identificação de termos que remetem à identidade étnica indígena e não especificamente o objeto de disputa da ação judicial. Tendo tais delimitações em consideração, é realizada uma primeira "leitura flutuante" (BARDIN, 1977, p. 60) para selecionar os julgados a serem analisados. A partir daí, a leitura individual de cada julgado é aprofundada.

Tendo em vista a competência da justiça estadual quanto a demandas envolvendo indígenas, a grande maioria dos processos encontrados nos tribunais estaduais refere-se a casos de indígenas que cometeram algum ilícito penal. Tendo em vista o disposto no artigo 56

\footnotetext{
${ }^{4}$ Para uma amostra desse argumento, remetemos a WAGNER, Daize Fernanda. Identidade étnica, índios e direito penal no Brasil: paradoxos insustentáveis. Revista Direito GV, [S.1.], v. 14, n. 1, p. 123-147, mai. 2018. Disponível em: 〈http://bibliotecadigital.fgv.br/ojs/index.php/revdireitogv/article/view/74844>. Acesso em: 2 Maio 2020.
} 
do Estatuto do Índio, Lei 6.001/1973, o simples fato de ser indígena implica na aplicação de minorante no cálculo da pena. Ocorre que nessa interpretação, a grande maioria dos julgados encontrados inicialmente reconhece a identidade indígena do réu, mas a desconsidera na aplicação da minorante, sob o argumento de que aquele indígena já está aculturado e, portanto, não faz mais jus a tal benefício. Nesses casos, percebeu-se que os tribunais, em sua maioria, parecem estar ainda vinculados e utilizando aquela percepção culturalista da identidade étnica, que não encontra abrigo na Convenção 169 da OIT e nem no reconhecimento do direito à diferença, estabelecido pela CF/88, artigo 231 .

Para o presente artigo, após essa primeira delimitação, passou-se a verificar também quais julgados mencionavam a Convenção 169 OIT em seu corpo. Portanto, serão tratadas apenas as decisões dos tribunais que mencionam a Convenção.

\section{DECISÕES DOS TRIBUNAIS DE JUSTIÇA DA REGIÃO NORTE}

A região Norte do Brasil compreende os estados do Acre, Amapá, Amazonas, Pará, Rondônia, Roraima e Tocantins. A região foi selecionada para esta análise por ser aquela na qual reside a maior parte da população indígena no Brasil, segundo dados do Censo Demográfico 2010, do Instituto Brasileiro de Geografia e Estatística (IBGE).

A busca dos julgados ocorreu nos endereços eletrônicos de cada um dos sete Tribunais estaduais da Região Norte, no mês de abril de 2020 e utilizou, na aba de pesquisa de jurisprudência destinada à pesquisa livre, a expressão "Convenção 169 OIT”.

Utilizando-se esses parâmetros, encontrou-se o total de 18 decisões que citam a Convenção 169 da OIT. Se tomarmos por base o primeiro critério de seleção utilizado pela pesquisa, que buscou julgados sobre identidade étnica indígenas nesses mesmos tribunais, a partir dos termos de busca índio(s), indígena(a), silvícola(s), aborígine(s) e autóctone(s), o número total de julgados encontrado foi de $244 .^{5}$ Estes estão assim distribuídos: no Tribunal de Justiça do estado do Acre (TJAC), 4 julgados; no Tribunal de Justiça do estado do Amapá (TJAP), um julgado; no Tribunal de Justiça do estado do Amazonas (TJAM), dois casos; no

\footnotetext{
${ }^{5}$ A título de esclarecimento, quando lançados tais termos de busca na aba de pesquisa livre de jurisprudência, o número de julgados é muito maior. Os 244 aqui referidos são aqueles que tratam apenas de aspectos relacionados a identidade e pertença étnica dos indígenas, que reduz a amostra significativamente. Nessa busca, o lapso temporal foi da data de promulgação da CF/88 até dezembro de 2018.
} 
Tribunal de Justiça do estado do Pará (TJPA), 168 julgados; no Tribunal de Justiça do estado de Rondônia (TJRO), 15 julgados; no Tribunal de Justiça do estado de Roraima (TJRR), 36 julgados; e no Tribunal de Justiça do estado de Tocantins, 18 julgados.

Os 18 julgados que referem a Convenção 169 da OIT estão assim distribuídos: nenhum no TJAC; nenhum no TJAP; 3 julgados no TJAM; 1 julgado no TJPA; 2 julgados no TJRO; 6 julgados no TJRR; e 6 no TJTO.

O fato de 18 julgados mencionarem a Convenção 169 da OIT não pode ser interpretado como se tivesse ocorrido em todos eles alguma espécie de controle de convencionalidade em relação ao vetusto Estatuto do Índio. Este classificava os indígenas em três categorias distintas, a depender do grau de integração em que se encontrassem. $\mathrm{O}$ artigo $4^{\mathrm{o}}$. dizia que:

\footnotetext{
Art $4^{\circ}$ Os índios são considerados:

I - Isolados - Quando vivem em grupos desconhecidos ou de que se possuem poucos e vagos informes através de contatos eventuais com elementos da comunhão nacional;

II - Em vias de integração - Quando, em contato intermitente ou permanente com grupos estranhos, conservam menor ou maior parte das condições de sua vida nativa, mas aceitam algumas práticas e modos de existência comuns aos demais setores da comunhão nacional, da qual vão necessitando cada vez mais para o próprio sustento;

III - Integrados - Quando incorporados à comunhão nacional e reconhecidos no pleno exercício dos direitos civis, ainda que conservem usos, costumes e tradições característicos da sua cultura.
}

A partir dessa classificação, os indígenas recebiam tratamento distinto. Ou seja, o Estatuto do Índio estabelecia uma gradação que era interpretada como se houvesse maneiras de ser mais ou menos indígena. A CF/88 rompeu com essa lógica e a Convenção 169 da OIT também, ao estabelecer expressamente no artigo $1^{\circ}, 2$, que a autoidentificação é o critério que estabelece a identidade e a pertença indígena. Portanto, os indígenas são indígenas independentemente do grau de contato e das relações que possam estabelecer com os nãoíndios e a dita sociedade envolvente.

Então, tendo isso em consideração, ao analisar o conteúdo dos 18 acórdãos, observase que em doze deles a menção à Convenção 169 da OIT não tem lugar na decisão em si. Destes 12 acórdãos, em 6 deles, a referência à Convenção aparece apenas relatório do julgado, na parte destinada a reproduzir os argumentos das partes. Neles, a norma internacional aparece apenas como um dos argumentos de defesa dos indígenas envolvidos, que pugnam pelo reconhecimento e aplicação da Convenção 169 da OIT. Em 5 deles, o uso da Convenção 169 da OIT ocorre apenas em jurisprudências colacionadas pelos relatores em 
seus votos, mas não aparece enquanto um argumento em si. Por fim, em um dos 12 julgados em que a Convenção 169 aparece, mas não no corpo do voto do relator, há a citação da Convenção, mas para afastar sua aplicação pois os indígenas envolvidos estaria já aculturados e, então, a eles não se aplicaria a Convenção 169 da OIT.

Em apenas seis julgados pode-se considerar que houve, por parte dos julgadores, um controle de convencionalidade, ou seja, somente nestes é possível evidenciar que a Convenção 169 da OIT é cotejada e implica em reconhecimento de seu conteúdo. Isso ocorre em 2 acórdãos do TJAM, nos quais o relator utilizou a Convenção 169 da OIT, inclusive em seu artigo 10, sem sequer ter sido mencionada pelo réu indígena. No TJRR um acórdão aplica a Convenção 169 da OIT, reconhece ser ela tratado internacional de direitos humanos com status supralegal e, então, reconhece o jus puniendi da comunidade indígena, afastando a punição estatal por caracterizar bis in idem. Por fim, no TJTO, 3 acórdãos utilizam-se da Convenção 169 da OIT, cotejando-a em face do Estatuto do Índio, para reconhecer a capacidade dos indígenas envolvidos nos julgamentos. Os julgados que realizaram controle de convencionalidade tiveram suas decisões proferidas nos anos de 2015 e 2017. Daí se pode inferir que a menção e até mesmo a aplicação da Convenção 169 da OIT pelos tribunais estaduais analisados está se ampliando à medida que seu tempo de vigência aumenta. Nos tribunais analisados, a Convenção só começa a aparecer nos julgados a partir do ano de 2007, com uma ocorrência no TJPA. Todos os demais julgados que mencionam a Convenção, ainda que não a apliquem, são posteriores ao ano de 2014.

A CF/88, anterior à Convenção 169 da OIT, já trazia reconhecimento jurídico inovador aos povos indígenas no Brasil. Portanto, a recepção da Convenção 169 da OIT não representava, nesse ponto, grande ruptura na ordem jurídica interna, pois essa mudança já havia sido realizada pela CF/88. O grande mérito da recepção da Convenção 169 da OIT, portanto, é o compromisso no plano internacional assumido pelo Brasil em relação a seus povos indígenas, agora em conformidade com o previsto no âmbito interno. (WAGNER, 2014).

Quando se considera a mostra de 244 julgados que discutem a identidade étnica de indígenas e o número de 6 julgados que se utilizaram da Convenção 169 da OIT, percebe-se que sua aplicação ainda é bastante tímida. Em grande parte dos julgados analisados, entendese que há violação da Convenção 169 da OIT, especificamente no que estabelece em seu artigo $1^{\circ}$, item 2 , na medida em que, em regra, não há menção alguma à Convenção. 
Considera-se que tais julgados estão em franco descompasso com os valores constitucionais inaugurados em 1988, no plano do direito interno, e os valores consagrados no plano internacional, a partir do resguardo dos direitos humanos em diferentes tratados e, mais especificamente, o reconhecimento a direitos próprios aos indígenas, como estabelece a Convenção 169 da OIT.

Seguindo a hierarquização das normas jurídicas, especialmente após a decisão do Supremo Tribunal Federal (STF) no RE 466.343-SP e HC 87.585-TO, esperava-se verificar a menção e aplicação da Convenção 169 da OIT em julgados envolvendo indígenas. Esperavase encontrar nos julgados a execução do controle difuso de convencionalidade, especialmente por se considerar que a Convenção 169 da OIT é tratado multilateral de direitos humanos.

Todavia, os resultados da pesquisa até aqui encontrados apontam para o sentido inverso: os Tribunais de Justiça da Região Norte ainda não romperam com a percepção assimilacionista do Estatuto do Índio, na medida em que referem em suas decisões os chamados graus de integração dos indígenas, tal como estabelecia artigo $4^{\circ}$ do Estatuto do Índio. Em regra, desconsideram a autoidentificação dos indígenas como critério suficiente para estabelecer sua identidade étnica, tal como prevê o artigo $1^{\circ}$ item 2 da Convenção 169 da OIT.

\section{CONSIDERAÇÕES FINAIS}

No Brasil, a $\mathrm{CF} / 88$, artigo $5^{\circ}$, parágrafo segundo, atribuiu aos tratados internacionais de proteção aos direitos humanos ratificados pelo Estado brasileiro a condição de fontes do sistema constitucional de proteção de direitos. (MAZZUOLI, 2011). Nessa direção, o princípio internacional pro homine, segundo o qual, em caso de conflito, deve o intérprete optar preferencialmente pela fonte que proporciona a norma mais favorável à pessoa protegida. (MAZZUOLI, 2011). Ora, o que se pretende é a otimização e a maximização dos sistemas interno e internacional, de proteção dos direitos e garantias individuais. (BIDART CAMPOS apud MAZZUOLI, 2011).

Todavia, ainda não é o que se encontra majoritariamente entre as decisões dos Tribunais estaduais da Região Norte, como observado. A pesquisa conduzida no projeto Identidades Étnicas em Juízo, na UNIFAP, ainda não foi concluída em sua integralidade. Todavia, até o presente foi possível identificar que, pelo menos nos tribunais investigados, a 
aplicação da norma internacional, a Convenção 169 da OIT, não ocorre em sua plenitude. O controle de convencionalidade difuso pode e deve ser ampliado no âmbito dos Tribunais estaduais.

Os povos indígenas têm sido protagonistas importantes a demandar a aplicação e reconhecimento efetivo da norma de direito internacional, Convenção 169 da OIT, que está alinhada com os valores e normas da $\mathrm{CF} / 88$.

Além deles, cabe mencionar as recentes normativas do Conselho Nacional de Justiça (CNJ) a demonstrar também uma mudança importante em relação à efetivação da Convenção 169 da OIT e mesmo da CF/88 no que se refere aos direitos humanos reconhecidos aos indígenas. Trata-se da Resolução n. 287/2019, aprovada em julho de 2019, que estabelece procedimentos ao tratamento das pessoas indígenas acusadas, rés, condenadas ou privadas de liberdade. Essa resolução apresenta diretrizes para assegurar os direitos dos indígenas no âmbito criminal no Poder Judiciário. Entre os principais aspectos por ela abordados, está a incorporação do critério da autodeclaração de indígenas, tal como estabelecido pela Convenção 169 da OIT. Além da Resolução, foi publicado um manual para orientar o cumprimento da Resolução, com 52 páginas.

Entende-se que o cumprimento do que estabelece a Resolução 287/2019 do CNJ pelos integrantes do Poder Judiciário representa um grande desafio, que implica em mudança significativa de percepção e aparelhamento adequado para que tenha êxito. Como é bastante recente, caberá acompanhar sua execução. De qualquer maneira, já se pode afirmar que a Resolução foi mais um importante passo no sentido de assegurar a efetividade da aplicação da Convenção 169 da OIT no plano do direito interno brasileiro.

\section{REFERÊNCIAS:}

ABRAMOVICH, Víctor. Das violações em massa aos padrões estruturais: novos enfoques e clássicas tensões no sistema interamericano de direitos humanos. Sur, Revista Internacional de Direitos Humanos, São Paulo , v. 6, n. 11, p. 6-39, Dez. 2009. Disponível em: $<$ http://www.scielo.br/scielo.php?script=sci_arttext\&pid=S180664452009000200002\&lng=en\&nrm=iso>. Acesso em: 01 maio 2020.

BARDIN, Laurence. Análise de conteúdo. Tradução de Luís Antero Reto e Augusto Pinheiro. Lisboa: Edições 70, 1977.

BARTH, Fredrik. Grupos étnicos e suas fronteiras. In: POUTIGNAT, Philippe; STREIFF- 
FENART, Jocelyne. Teorias da etnicidade. Tradução de Elcio Fernandes. São Paulo: Fundação Editora da UNESP, 1998.

BIDART CAMPOS, German J. Tratado elemental de derecho constitucional argentino. Tomo III. El derecho internacional de los derechos humanos y la reforma constitucional de 1994. Buenos Aires: Ediar, 1995.

BOHMER, Martin. Prestamos y Adquisiciones. La utilización del derecho extranjero como una estrategia de creación de autoridad democrática y constitucional. Disponível em: <http://www.law.yale.edu/documents/pdf/sela/ MartinBohmer_Spanish_.pdf>. Último acesso em: Nov. 2009.

BRASIL, Constituição da República Federativa do Brasil. Disponível em: http://www.planalto.gov.br/ccivil_03/constituicao/ConstituicaoCompilado.htm. Acesso em: 14 set. 2018.

BRASIL. Conselho Nacional de Justiça. Resolução n. 287, de de 2019. Disponível em: https://atos.cnj.jus.br/atos/detalhar/2959. Acesso em: 2 maio 2020.

BRASIL. Conselho Nacional de Justiça. Manual Resolução n. 287/2019: procedimentos relativos a pessoas indígenas acusadas, rés, condenadas ou privadas de liberdade. Orientações a Tribunais e Magistrados para cumprimento da Resolução 287/2019 do Conselho Nacional de Justiça. Disponível em: https://www.cnj.jus.br/cnj-publica-manual-sobre-indigenasprocessados-criminalmente/. Acesso em 2 maio 2020.

BRASIL, Lei n. 6.001, de 19 de dezembro de 1973. Dispõe sobre o Estatuto do Índio. Disponível em: http://www.planalto.gov.br/ccivil_03/leis/16001.htm. Acesso em: 14 set. 2018.

BRASIL. Decreto n. 5.051, de 19 de abril de 2004. Promulga a Convenção n. 169 da Organização Internacional do Trabalho - OIT sobre Povos Indígenas e Tribais. . Disponível em: http://www.planalto.gov.br/ccivil_03/_ato2004-2006/2004/decreto/d5051.htm. Acesso em: 14 set. 2018.

BRASIL. Tribunal Regional Federal da Primeira Região. Apelação Cível n. 000250570.2013.4.01.3903/PA. Relator Des. Jirair Aram Meguerian. Decisão em 6 dez. 2017. Disponível em: https://processual.trf1.jus.br/consultaProcessual/processo.php Acesso em: 2 maio 2020.

CUNHA, Manuela Carneiro da. Os direitos dos índios: ensaios e documentos. São Paulo: Brasiliense, 1987.

GLASS, Verena et al. (Org). Protocolos de Consulta Prévia e o direito à livre determinação. São Paulo: Fundação Rosa Luxemburgo; CEPEDIS, 2019.

GUSTIN, Miracy Barbosa de Sousa. DIAS, Maria Tereza Fonseca. (Re)pensando a Pesquisa Jurídica: Teoria e Prática. 4.ed. Belo Horizonte: Del Rey, 2013. 
INSTITUTO BRASILEIRO DE GEOGRAFIA E ESTATÍSTICA. Censo demográfico 2010. Disponível em: http://indigenas.ibge.gov.br/ . Acesso em 2 maio 2020.

LAPIERRE, Jean William. Prefácio. In: POUTIGNAT, Philippe; STREIFF-FENART, Jocelyne. Teorias da etnicidade. Seguido de grupos étnicos e suas fronteiras de Fredrik Barth. Tradução de Elcio Fernandes. São Paulo: Fundação Editora da UNESP, 1998.

LEAL, Mônia Clarissa Hennig; ALVES, Felipe Dalenogare. O controle de convencionalidade e o Judiciário brasileiro: a sua aplicação pelo Tribunal Superior do Trabalho como forma de proteger a dignidade da mão-de-obra (vedação de terceirização de atividade-fim) no case Carneiro Távora v. Telemar Norte Leste e Contax. Revista Investigação

Constitucional, Curitiba, v. 4, n. 1, p. 109-128, Abr. 2017. Disponível em: $<$ http://www.scielo.br/scielo.php?script=sci_arttext\&pid=S2359-

56392017000100109\&lng=en\&nrm=iso>. Acesso em: 2 Maio 2020.

LIMA, Roberto Kant de; BAPTISTA, Bárbara Gomes Lupetti. Como a antropologia pode contribuir para a pesquisa juridica? Um desafio metodológico. Anuário Antropológico 2013, Brasília, v. 39, n. 1, p. 9-37, 2014.

LUCIANO, Gersem dos Santos. O índio brasileiro: o que você precisa saber sobre os povos indígenas no Brasil de hoje. Brasília: Ministério da Educação, Secretaria de Educação Continuada, Alfabetização e Diversidade; LACED/Museu nacional, 2006.

MAC GREGOR, Eduardo Ferrer. El control difuso de convencionalid en el Estado constitucional. In: FIX-ZAMUDIO, Héctor; VALADÉS, Diego. (Coords.). Formación y perspectiva del Estado Mexicano. Mexico: El Colegio Nacional-UNAM, 2010, p. 151-188.

MAZZUOLI, Valerio de Oliveira. O controle jurisdicional da convencionalidade das leis. 2. Ed. São Paulo: RT, 2011.

MEDEIROS; Fernanda L.F. de; PETTERLE, Selma R. Observatórios de Jurisprudência: um modo de (re)pensar o direito do século XXI. In: Encontro de Internacionalização do CONPEDI, I, 2015, Barcelona. Anais... Barcelona: Ediciones Laborum, 2015. p. 335.

ORGANIZAÇÃO INTERNACIONAL DO TRABALHO. Convenção n. 169 sobre povos indígenas e tribais e resolução referente à ação da OIT. Brasília: OIT, 2011.

POUTIGNAT, Philippe; STREIFF-FENART, Jocelyne. Teorias da etnicidade. Seguido de grupos étnicos e suas fronteiras de Fredrik Barth. Tradução de Elcio Fernandes. São Paulo: Fundação Editora da UNESP, 1998.

SILVA, Isabelle Braz Peixoto da. Vilas de índios no Ceará Grande: dinâmicas locais sob o Diretório Pombalino. Campinas: Pontes Editores, 2005.

SILVA, Roberto Luiz. Direito Internacional Público. 4. Ed. Belo Horizonte: Del Rey, 2010.

SOUZA FILHO, Carlos Frederico Marés de. O renascer dos povos indígenas para o

Direito. Curitiba: Juruá, 1998.

Rev. de Direitos Humanos em Perspectiva | e-ISSN: 2526-0197 | Evento Virtual | v. 6 | n. 1 |

p. 18-37 | Jan/Jun. 2020 
VAL, Eduardo Manuel; OLIVEIRA, Thiago Aleluia F. de. O controle jurisdicional de convencionalidade: a práxis dos Tribunais Constitucionais do Chile e do Brasil. In:

ALVAREnGA, A. V. M. et al. (Org.). Justiça e Cidadania na América Latina: debates no século XXI. Vol. 1. Capivari de Baixo: Editora FUCAP, 2016, p. 141-160.

WAGNER, Daize Fernanda. Dez anos após a entrada em vigor da Convenção 169 da OIT no Brasil: um olhar sob a perspectiva da efetividade. In: CONPEDI; UFSC. (Org.). Direito Internacional dos Direitos Humanos II. 1ed.Florianópolis: CONPEDI, 2014, p. 247-263.

WAGNER, Daize Fernanda; CARMO, Jéssica Araújo; JENNINGS, Mário Guilherme Corrêa. Identidades étnicas em juízo: a identidade étnica indígena na visão dos tribunais estaduais da região norte. In: Congresso Brasileiro de Direito Socioambiental, VII, 2018, Goiânia. Anais do VII Congresso Brasileiro de Direito Socioambiental. Curitiba: CEPEDIS, 2018, p. 63.

WAGNER, Daize Fernanda. Identidades étnicas em juízo: o caso Raposa Serra do Sol. Belo Horizonte: Initia Via, 2019.

WEBER, Max. Economia e sociedade: fundamentos da sociologia compreensiva. 3. Ed. Tradução de Regis Barbosa e Karem Elsabe Barbosa. Brasília: Editora da Universidade de Brasília, 1994. 